\title{
Predictors of additional intraocular pressure reduction in patients changed to latanoprost/timolol fixed combination
}

\author{
Eric Sellem, Jean François Rouland², Christophe Baudouin³, Alain Bron4, Philippe Denis5, Jean-Philippe Nordmann6 \\ and Jean Paul Renard ${ }^{7}$
}

\begin{abstract}
Background: Given the growing number of ocular hypotensive medications available, it is important to be able to predict a positive response to therapy. The purpose of the present study was to identify predictors of an additional 10\% intraocular pressure (IOP) reduction after 12 weeks of treatment with latanoprost/timolol fixed combination (FC) in patients requiring a change in their previous ocular hypotensive medication.

Methods: This multicenter, open-label, prospective, phase Illb study included subjects $\geq 18$ years of age with openangle glaucoma (OAG) or ocular hypertension $(\mathrm{OHT})$. Eligible subjects had baseline $\mathrm{IOP} \geq 21 \mathrm{mmHg}$ and insufficient response to current beta-blocker monotherapy. The primary efficacy analysis (logistic regression) identified predictors of a positive response after 12 weeks of latanoprost/timolol FC.

Results: The intent-to-treat (ITT) population included 383 subjects treated with $\geq 1$ drop of FC and having $\geq 1$ follow-up IOP assessment. Mean IOP was $22.19 \pm 2.16 \mathrm{mmHg}$ at baseline and was reduced by $5.42 \pm 2.71 \mathrm{mmHg}$ at study end. In all, 325 (84.9\%) subjects had a positive response to latanoprost/timolol FC; the response rate was similar across groups: OAG $(n=208 ; 82.7 \%)$; OHT $(n=161 ; 87.6 \%) ; O A G+O H T(n=14 ; 85.7 \%)$. Higher baseline IOP (odds ratio: 1.284; $95 \%$ confidence interval [CI]: 1.101, 1.497; $\mathrm{p}=0.0014$ ) and absence of adverse events (odds ratio: 0.318; 95\% Cl: 0.161, 0.629; $p=0.0010$ ) were significant predictors of positive response. Age, gender, ethnic origin, diagnosis, family history of OAG/ $\mathrm{OHT}$, corneal thickness, and concomitant systemic beta-blocker were not significant predictors of a positive response in the ITT analysis. The FC was well tolerated. The most common adverse events were related to the eye and were consistent with known adverse events associated with latanoprost and timolol.

Conclusions: These results support the use of latanoprost/timolol FC in patients whose IOP is insufficiently controlled on beta-blocker monotherapy. Patients with higher baseline IOP levels and who do not experience adverse events while on therapy are most likely to achieve a positive response to latanoprost/timolol FC.
\end{abstract}

Trial Registration: Study registration number: NCT00230763

\section{Background}

Disease progression in patients with open-angle glaucoma (OAG) or ocular hypertension (OHT) can be slowed or stopped by reducing intraocular pressure (IOP) levels though the use of ocular hypotensive agents [1-5]. Firstchoice options for medical treatment of elevated IOP levels usually are topical beta-blockers such as timolol maleate

* Correspondence: esellem@aol.com

${ }^{1}$ Centre Ophtalmologique Kléber, 50, Cours Franklin Roosevelt, 69006 Lyon, France

Full list of author information is available at the end of the article and prostaglandin analogs such as latanoprost [6]. Many patients require more than one IOP-lowering drug [5] resulting in complex medication regimens that may be difficult to maintain and that can lead to non-compliance [6]. Physicians should try to simplify medication regimens in order to maximize patient compliance [7-10]. In these cases, combining two medications into a fixed combination (FC) is preferable to prescribing two individual therapies [6]. Where individual treatment is available in a FC, ease of use and potential reduction of side effects argue in favor of their use [6]. 
Latanoprost/timolol FC became commercially available in France in 2002 and is indicated for reduction of IOP in patients with OAG and OHT who are insufficiently responsive to monotherapy with topical beta-blockers or prostaglandin analogs [11]. This FC has been shown to be effective and well tolerated [12-17]. Given the growing number of ophthalmic medications available, our goal was to identify predictors of a positive response (i.e., an additional $10 \%$ IOP reduction) in patients with OAG or OHT who required a change in their previous ophthalmic medication and who were switched to latanoprost/timolol FC.

\section{Methods}

\section{Study design}

This was a prospective, open-label, multicenter, phase IIIb study conducted in France between October 8, 2005, and October 5, 2007 (NCT00230763). The final protocol and informed consent documents were reviewed and approved by the Independent Ethics Committee (Comité Consultatif de Protection des Personnes dans la Recherche Biomédicale de Lyon B, France). The study complied with all International Conference on Harmonization Good Clinical Practice guidelines and with the Declaration of Helsinki. Written informed consent was obtained prior to a subject entering the study (i.e., before initiation of protocol-specified procedures).

\section{Subjects}

Male or female subjects $\geq 18$ years of age diagnosed with $\mathrm{OAG}$ or OHT with an IOP $\geq 21 \mathrm{mmHg}$ were eligible if they were being treated with an ophthalmic beta-blocker monotherapy and if, in the investigator's opinion, they required a change in ocular hypotensive therapy because of an insufficient response to treatment. Excluded were those currently treated or treated within the prior month with any ophthalmic hypotensive agent other than a beta-blocker; with any contraindication to latanoprost or timolol including medical conditions that would preclude use of the study medication; with known intolerance to benzalkonium chloride or any excipient contained in the study medication; with severe visual field loss and/or optic disc damage; who had participated in another clinical trial within the prior 30 days; who had been previously treated with latanoprost/timolol FC; or who, in the opinion of the investigator, had an ophthalmic or general medical condition that prevented participation. Also excluded were women of childbearing potential who were not using adequate contraceptive methods or who were pregnant or nursing.

\section{Treatments and assessments}

At the baseline visit, demographic data and medical, ocular, and treatment histories were recorded, and biomicroscopy and ophthalmoscopy were performed. Prior to pupil dilation, best-corrected visual acuity was measured (Monoyer scale for distant vision and Parinaud scale for near vision), and IOP was measured by pulse air tonometry or calibrated Goldmann applanation tonometry. With pulse air tonometry, three IOP measurements were performed, and the mean value was used in analyses; with Goldmann applanation tonometry, only one measurement was required. Both eyes were examined, even if only one eye was to be treated with latanoprost/timolol FC. The Glaucoma Symptom Scale (GSS) [18] and a satisfaction questionnaire developed for this study that included items regarding medication compliance were completed by the subject. The GSS, a brief, simple, and reliable instrument, has been found to discriminate well between individuals with and without glaucoma [18]. The GSS has been used to evaluate the personal burden of glaucoma in a variety of settings [19-21].

At the baseline visit, subjects stopped the previous ocular hypotensive therapy and were given sufficient latanoprost/ timolol FC for the next 4 weeks. Subjects were instructed to instill the FC in each affected eye once daily in the evening starting the following day. Approximately 4 weeks postbaseline, subjects returned for an intermediate study visit at which time IOP was measured prior to pupil dilation using the method employed at baseline. The subject completed the GSS and satisfaction/compliance questionnaire, and physicians assessed the presence of adverse events and the global response to FC treatment. Each adverse event whether observed, elicited, or reported spontaneously was recorded, and the investigator graded its intensity (mild, moderate, severe) and evaluated whether the event was related to the FC. Serious adverse events were those that resulted in death, that were life-threatening, that required or prolonged hospitalization, that resulted in persistent or significant disability/incapacity, or that resulted in congenital anomaly/birth defect. At this intermediate visit, subjects were given sufficient latanoprost/timolol FC for the next 8 weeks. After 12 weeks of FC therapy, subjects returned for a final study visit at which time the assessments done at week 4 were repeated, visual acuity was measured, ophthalmoscopy and biomicroscopy were performed, and ophthalmic abnormalities were summarized by severity.

\section{Endpoints and analyses}

The primary efficacy analysis was performed on the intentto-treat (ITT) population defined as all subjects who received at least one dose of latanoprost/timolol FC and who had at least one on-study IOP evaluation. The per protocol (PP) population excluded those in the ITT population with a major protocol deviation. In analyses of IOP level, visual acuity, and GSS scores, the mean value from both eyes was used if both eyes were treated with latanoprost/ timolol FC; otherwise, only data for the treated eye were included in analyses. The last observation carried forward method, using the last available postbaseline observation, was used to impute missing continuous data. The safety 
population included subjects who received at least one dose of latanoprost/timolol FC.

The primary efficacy endpoint was a positive response to latanoprost/timolol FC defined as an IOP reduction $>10 \%$ from baseline after 12 weeks of treatment. A stepwise logistic regression model was used to evaluate associations between possible baseline and on-treatment predictors of a positive response. Potential predictors included age, gender, ethnic origin, family history of $\mathrm{OAG}$, family history of OHT, concomitant systemic treatment with beta-blockers, diagnosis $(\mathrm{OAG} / \mathrm{OHT} / \mathrm{OAG}$ in one eye and $\mathrm{OHT}$ in the other eye), IOP at baseline, corneal thickness, compliance, and presence/absence of adverse events as well as interactions between gender and diagnosis. Subjects with missing values for predictors were excluded from analyses of affected variables. Variables with $\geq 20 \%$ missing data were excluded. Covariates were included in the stepwise model with the significance level for entry fixed at $5 \%$ and the significance level for retention fixed at $10 \%$. P-values and 95\% confidence intervals (CIs) for the odds ratios were calculated. In case of a difference of $>10 \%$ between the number of subjects in the ITT and PP populations, a secondary analysis for the primary efficacy endpoint was conducted on the PP population.

Secondary efficacy endpoints were summarized for the ITT population overall and stratified by gender and diagnosis. Endpoints included absolute and relative IOP changes from baseline to week 12; percentages of subjects achieving a $\geq 5 \%$ or $\geq 15 \%$ IOP reduction from baseline at week 12 ; percentages of subjects achieving IOP levels of $<18$ and $<16 \mathrm{mmHg}$ at week 12; absolute and relative visual acuity changes from baseline to week 12; absolute changes in GSS scores (total score, non-visual symptom score, and visual symptom score) from baseline to weeks 4 and 12; subject satisfaction with FC treatment at baseline and weeks 4 and 12; and investigator's global assessment of response to FC treatment at weeks 4 and 12. The significance of potential predictors of achieving specified percentage IOP reductions and of reaching specified IOP levels at week 12 was analyzed by stepwise logistic regression models. The same 11 covariates that were included in the primary analysis were evaluated. Absolute and relative IOP changes, visual acuity changes, and changes in GSS scores were evaluated using analysis of covariance (ANCOVA) models that included the relevant baseline score as a covariate; adjusted (least square) and unadjusted means were calculated, and pairwise differences between etiologies were summarized along with standard errors, p-values, and 95\% CIs. GSS scores were transformed to a scale of 0 (maximum complaint) to 100 (no complaint), where transformed score $=$ score*25. Data concerning patient satisfaction/compliance and investigators' assessments of global response to treatment were tabulated and summarized. At baseline, the number of subjects on each type of beta-blocker was summarized as were IOP levels prior to beta-blocker initiation (if available), beta-blocker treatment duration, and reason for treatment change (investigator judgment).

Data reflecting systemic and ophthalmic adverse events were tabulated and summarized for the safety population. Adverse events were classified by System Organ Class and preferred term according to the Medical Dictionary for Regulatory Activities (MedDRA) Version 11.1. Percentages of subjects with relevant ophthalmic abnormalities at week 12 were compared across etiologies using the chi-square or Fisher's exact test.

The sample size calculation was based on the assumptions that $20 \%$ to $50 \%$ of subjects would achieve IOP reduction $>10 \%$ after 12 weeks of latanoprost/timolol FC and that the same percentage of subjects was exposed to the predictive factor identified (e.g., age above $\mathrm{n}$ years). With an odds ratio $=2$, a significance level $=5 \%$, and power $=$ $80 \%, 395$ subjects were required.

\section{Results}

One hundred and twenty-one centers screened 395 subjects and assigned all of them to latanoprost/timolol FC (Figure 1). In all, 391 subjects received at least one dose of the FC and were included in the safety population; 344 completed the study while 21 discontinued for reasons related to the study drug and 26 discontinued for reasons unrelated to latanoprost/timolol FC. The ITT population included 383 subjects, and the PP population included the 316 subjects without a major protocol deviation. Of the 98 major protocol deviations recorded in 70 subjects, 67 of whom were in the ITT population, most related to noncompliance with inclusion/exclusion criteria ( $\mathrm{n}=50)$, not using study drug at the time of IOP assessment ( $n=20)$, or use of commercial latanoprost/timolol FC during the study $(\mathrm{n}=20)$.

The treatment group, which was overwhelmingly Caucasian, included 182 males and 209 females with a mean age of 63.0 years (Table 1). At screening, the majority of subjects were diagnosed with OAG, more than half had at least one concomitant condition at screening, and most were being treated with timolol $(206 / 383,53.8 \%)$ or carteolol $(144 / 383,37.6 \%)$. Subjects had been on the screening therapy for an average of 2.5 years and had a mean IOP of approximately $24 \mathrm{mmHg}$ in both eyes prior to initiating beta-blocker monotherapy. Insufficient efficacy was the primary reason given by investigators for switching to latanoprost/timolol FC. The median duration of latanoprost/ timolol FC treatment was 89.0 days (range, 3 to 183 days).

At week 12, a positive response (IOP reduction $>10 \%$ from baseline) to latanoprost/timolol FC was obtained in $325 / 383(84.9 \%)$ subjects in the ITT population (Table 2). No clinically significant difference in responder rates was noted with regard to diagnosis or gender. Of the 10 potential predictors included into the logistic regression analysis, two were associated with a positive IOP response: higher 


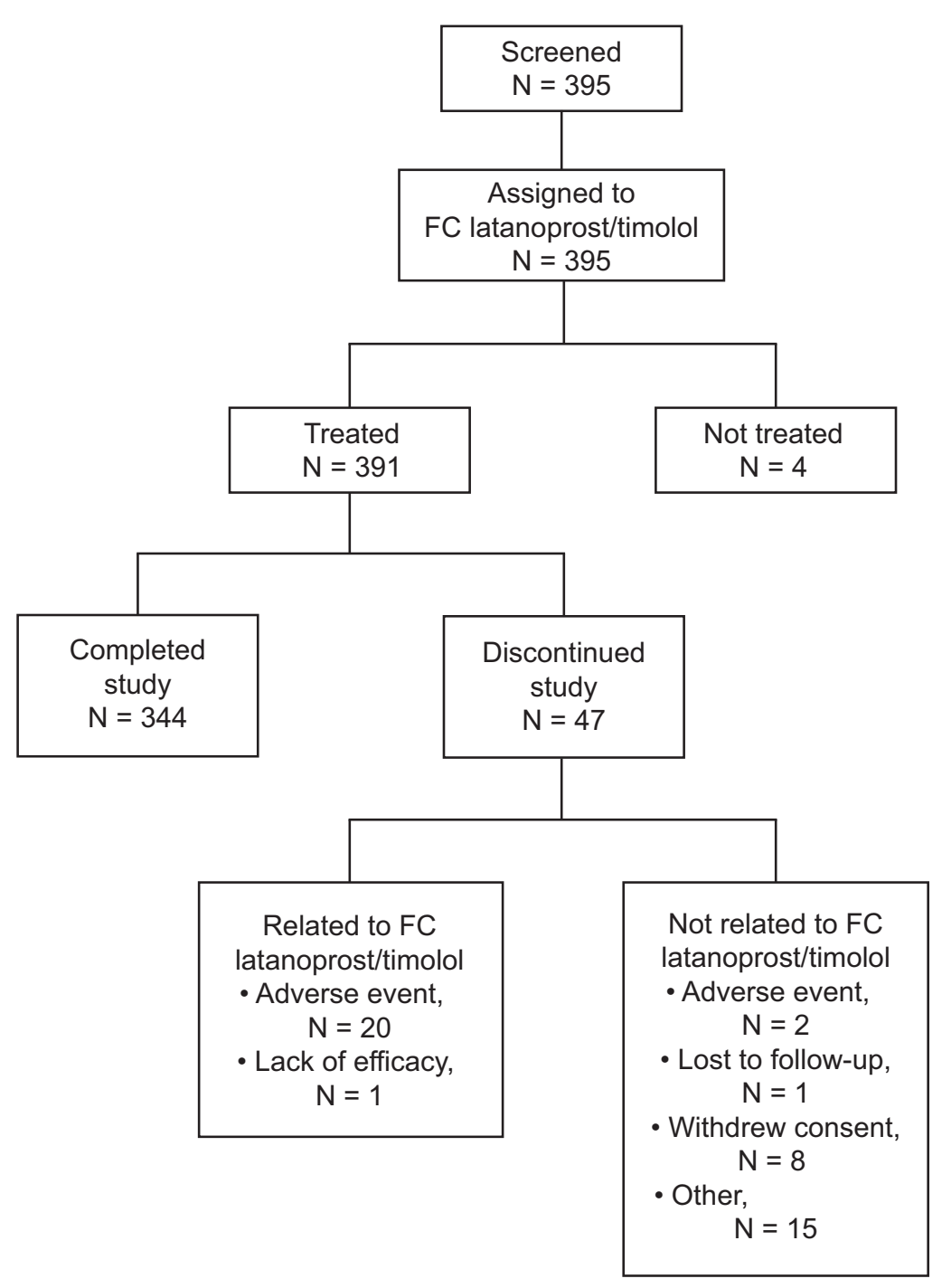

Figure 1 Subject disposition. $\mathrm{FC}=$ fixed combination.

baseline IOP (parameter estimate, 0.25 ; odds ratio $[95 \%$ $\mathrm{CI}], 1.284$ [1.101, 1.497]; $\mathrm{p}=0.0014)$ and absence of adverse events (parameter estimate, -1.15 ; odds ratio [95\% $\mathrm{CI}], 0.318$ [0.161, 0.629]; $\mathrm{p}=0.0010$ ). (Note that the eleventh variable, compliance, was not included in this analysis because data were missing for $\geq 20 \%$ of subjects.) In the PP population, 288/316 (91.1\%) subjects had a positive response. In this analysis population, higher baseline IOP but not absence of adverse events was significantly associated with a positive response to latanoprost/timolol FC; age was included in the model $(\mathrm{p}=0.0332)$, but the odds ratio was close to 1 (1.045), suggesting that age had little clinical relevance.

The relative overall mean IOP reduction from baseline to week 12 of $24.10 \pm 11.35 \%$ reflected a mean absolute change of $-5.42 \pm 2.71 \mathrm{mmHg}$ from the baseline mean of
$22.19 \pm 2.16 \mathrm{mmHg}$ (Table 3). The hypotensive effect was observed as soon as the week 4 visit when the mean IOP level was $16.98 \pm 2.46 \mathrm{mmHg}$. Absolute and relative IOP changes were similar across diagnosis and gender groups. Results of ANCOVA confirmed that diagnosis did not significantly influence IOP changes.

Reductions in IOP from baseline to week 12 of at least $5 \%$ or $15 \%$ were obtained in $339 / 383(88.5 \%)$ and $298 / 383$ (77.8\%) of subjects, respectively (Table 4). Thus, 298 of 325 responders $(91.7 \%)$ also achieved a $15 \%$ or greater decrease in IOP. Logistic regression analyses revealed that, as for the primary endpoint, two factors predicted a reduction in IOP of $\geq 5 \%$ and $\geq 15 \%$ : higher IOP at baseline and absence of adverse events $(\mathrm{p}=0.02$ for all). Again, neither diagnosis nor gender was a significant predictor of response. An IOP level $<18 \mathrm{mmHg}$ was achieved by $255 /$ 
Table 1: Demographic and baseline characteristics of subjects assigned to treatment, $\mathrm{N}=391$

\begin{tabular}{|c|c|}
\hline Gender, n (\%) & \\
\hline Male & $182(46.5)$ \\
\hline Female & $209(53.5)$ \\
\hline \multicolumn{2}{|l|}{ Age, years } \\
\hline Mean \pm SD & $63.0 \pm 11.8$ \\
\hline Range & $18-87$ \\
\hline \multicolumn{2}{|l|}{ Race, n (\%) } \\
\hline Caucasian & $381(97.4)$ \\
\hline Other & $10(2.6)$ \\
\hline \multicolumn{2}{|l|}{ Primary diagnosis* } \\
\hline OAG, $\mathrm{n}$ & 227 \\
\hline $\begin{array}{l}\text { Time since diagnosis, years, } \\
\text { Mean (Range) }\end{array}$ & $5.0(0.0-25.2)$ \\
\hline $\mathrm{OHT}, \mathrm{n}$ & 181 \\
\hline $\begin{array}{l}\text { Time since diagnosis, years, } \\
\text { Mean (Range) }\end{array}$ & $4.1(0.0-24.5)$ \\
\hline \multicolumn{2}{|l|}{ Family history of OAG or OHT, n (\%)† } \\
\hline Yes & $208(54.3)$ \\
\hline No & $162(42.3)$ \\
\hline Unknown/not recorded & $13(3.4)$ \\
\hline \multicolumn{2}{|l|}{ Central corneal thickness $† \S$} \\
\hline Mean \pm SD & $559.0 \pm 37.6$ \\
\hline Range & $450-662$ \\
\hline \multicolumn{2}{|l|}{ Concomitant conditions, n (\%) } \\
\hline Any such condition & $217(55.5)$ \\
\hline Vascular disorder & $126(32.2)$ \\
\hline Ophthalmic disease & $116(29.7)$ \\
\hline $\begin{array}{l}\text { Metabolism and nutrition } \\
\text { disorder }\end{array}$ & $102(26.1)$ \\
\hline
\end{tabular}

*Seventeen subjects had different diagnoses between eyes. +Intent-to-treat population: $\mathrm{n}=383$.

\$Data not recorded for 17 subjects.

$\mathrm{OAG}=$ open-angle glaucoma; $\mathrm{OHT}=$ ocular hypertension; $\mathrm{SD}=$ standard deviation.

$383(66.6 \%)$ subjects, and an IOP $<16 \mathrm{mmHg}$ was noted in 128/383 (33.4\%; Table 4). Lower baseline IOP and thinner corneas were significant predictors of both IOP $<16 \mathrm{mmHg}$ and $<18 \mathrm{mmHg}$; absence of adverse events was significantly associated with reaching an IOP of $<18 \mathrm{mmHg}$.

On average, subjects had good visual function at baseline (Monoyer scale, $8.50 \pm 1.99$; Parinaud scale, $2.30 \pm 1.18$ ) and experienced little change by week 12 (change in Monoyer scale, $0.03 \pm 0.80$; change in Parinaud scale, -0.05 \pm 0.71 ). No clinically relevant changes in glaucoma symp- toms were observed between baseline and week 12 as reflected by minimal changes in the global GSS score as well as by the non-visual and visual GSS subscale scores (Table 5).

At the end of the study, 292/319 (91.5\%) subjects responding to the satisfaction/compliance questionnaire indicated that they were "very satisfied" or "satisfied" with their ocular hypotensive therapy, an improvement from the $246 / 313(78.6 \%)$ expressing this level of satisfaction with the monotherapy administered at the time of the switch to latanoprost/timolol FC. Subject-reported medication compliance (instilling drops "every day without exception") also improved from $65 \%$ under previous beta-blocker monotherapy to $81 \%$ with latanoprost/timolol FC. Nearly $90 \%$ of investigators rated the FC as "effective" at the end of the study.

No death occurred among study participants. Five subjects experienced a total of six treatment-emergent serious adverse events, none of which was considered by investigators to be treatment-related. Among the 391 subjects in the safety population, $89(22.8 \%)$ experienced at least one all causality adverse event, and $22(5.6 \%)$ discontinued due to an adverse event (Table 6). Eleven all causality adverse events were considered to be severe in intensity. Sixty subjects $(15.3 \%)$ experienced at least one treatment-related adverse event; such events led to study discontinuation for 20 (5.1\%) subjects. "Eye disorders" was the System Organ Class most frequently involved, and the most commonly reported treatment-related ocular adverse events were eye irritation $(n=5)$, hyperemia, $(n=4)$, dryness $(n=4)$, pruritis $(n=3)$, and conjunctivitis $(n=3)$. The incidence of ophthalmic abnormalities was similar at baseline (201/383 [52.5\%]) and week $12(195 / 383$ [50.9\%]) but was significantly greater at the end of the study among subjects with OAG versus OHT (124/195 [63.6\%] versus 68/155 [43.9\%], respectively; $\mathrm{p}<0.001)$.

\section{Discussion}

The goal of this 12-week, prospective, open-label, multicenter study was to identify predictors of a positive response, defined as an additional 10\% IOP reduction, to latanoprost/timolol FC in patients with $\mathrm{OAG}$ or $\mathrm{OHT}$ whose IOP was insufficiently controlled on beta-blocker monotherapy and who required a change in their previous ophthalmic medication. A positive response was observed in $84.9 \%$ subjects in the ITT population, and patients most likely to achieve such a response were those with higher baseline IOP levels and those who did not experience adverse events while on treatment. Other factors tested, including age, gender, ethnic origin, diagnosis, family history, corneal thickness, and concomitant use of a systemic beta-blocker, were not significant predictors of a positive response. However, in the PP population (which included only patients without a major protocol violation), age, but 
Table 2: Subjects achieving a positive response to latanoprost/timolol FC* (ITT population)

\begin{tabular}{lcccc} 
& All & OAG & OHT & N= 161 \\
& $\mathbf{N}=\mathbf{3 8 3}$ & $\mathbf{N}=\mathbf{2 0 8}$ & $\mathbf{N}=\mathbf{1 4}$ \\
Positive response, $\mathbf{n}(\%)$ & $325(84.9)$ & $172(82.7)$ & $141(87.6)$ & $12(85.7)$ \\
Male, $\mathbf{N}=179$ & $156(87.2)$ & & \\
Female, $\mathrm{N}=204$ & $169(82.8)$ & & \\
\hline
\end{tabular}

*Positive response $=>10 \%$ IOP reduction from baseline to week 12 .

Both = both OAG and OHT; $F C=$ fixed combination; $I O P=$ intraocular pressure; $I T T=$ intent-to-treat population; $\mathrm{OAG}=$ open-angle glaucoma;

$\mathrm{OHT}=$ ocular hypertension.

not absence of adverse events, was a significant predictor of positive response. The predictive power of initial IOP, absence of adverse events, and age with regard to IOP reduction parallels results of previous studies. Higher baseline IOP levels have been associated with greater IOP reductions, due in part to regression to the mean [22-26]. Negative associations have been found between medication-related adverse events and both compliance $[7,27]$ and persistence [28]; it is intuitive that patients who do not take their ocular hypotensive medication as prescribed cannot obtain their full IOP-lowering benefit. Finally, older age has been identified as a risk factor for progression of glaucoma to blindness [4,29-31].

The effectiveness of latanoprost/timolol FC in reducing IOP levels has been demonstrated in randomized, doublemasked, controlled clinical trials [12-17], and switch studies such as ours are not appropriate for comparing therapies with regard to efficacy. Compared with other studies with

Table 3: IOP changes from baseline to week 12 by diagnosis and gender, mean \pm SD (ITT population)

\begin{tabular}{|c|c|c|c|c|}
\hline \multirow[b]{2}{*}{ IOP } & \multirow[b]{2}{*}{$\begin{array}{c}\text { All } \\
\mathbf{N}=383\end{array}$} & \multicolumn{3}{|c|}{ Diagnosis } \\
\hline & & $\begin{array}{c}\text { OAG } \\
N=208\end{array}$ & $\begin{array}{c}\text { OHT } \\
N=161\end{array}$ & $\begin{array}{c}\text { Both } \\
N=14\end{array}$ \\
\hline Baseline, $\mathrm{mmHg}$ & $22.19 \pm 2.16$ & $21.95 \pm 2.27$ & $22.40 \pm 1.97$ & $23.36 \pm 2.19$ \\
\hline $\begin{array}{l}\text { Change from baseline to week } 12, \\
\mathrm{mmHg}\end{array}$ & $-5.42 \pm 2.71$ & $-5.34 \pm 2.76$ & $-5.40 \pm 2.60$ & $-6.71 \pm 2.95$ \\
\hline \multirow[t]{2}{*}{ Change from baseline to week $12, \%$} & $-24.10 \pm 11.35$ & $-24.06 \pm 11.70$ & $-23.82 \pm 10.92$ & $-28.07 \pm 10.86$ \\
\hline & $\begin{array}{c}\text { Male } \\
N=179\end{array}$ & & $\begin{array}{l}\text { Female } \\
N=204\end{array}$ & \\
\hline Baseline, $\mathrm{mmHg}$ & $22.29 \pm 2.13$ & & $22.10 \pm 2.20$ & \\
\hline Week 12, mmHg & $16.53 \pm 2.55$ & & $16.99 \pm 2.67$ & \\
\hline $\begin{array}{l}\text { Change from baseline to week } 12, \\
\mathrm{mmHg}\end{array}$ & $-5.76 \pm 2.77$ & & $-5.11 \pm 2.62$ & \\
\hline Change from baseline to week $12, \%$ & $-25.51 \pm 11.38$ & & $-22.87 \pm 11.20$ & \\
\hline
\end{tabular}

Both = OAG and OHT; IOP = intraocular pressure; ITT = intent-to-treat population;

$\mathrm{OAG}=$ open-angle glaucoma; $\mathrm{OHT}=$ ocular hypertension; $\mathrm{SD}=$ standard deviation . 
Table 4: Subjects achieving prespecified IOP outcomes by diagnosis and gender, $\mathbf{n}(\%)$ (ITT population)

\begin{tabular}{|c|c|c|c|c|}
\hline \multirow[b]{2}{*}{ Patients with: } & \multirow[b]{2}{*}{$\begin{array}{c}\text { All } \\
N=383\end{array}$} & \multicolumn{3}{|c|}{ Diagnosis } \\
\hline & & $\begin{array}{c}\text { OAG } \\
N=208\end{array}$ & $\begin{array}{c}\text { OHT } \\
N=161\end{array}$ & $\begin{array}{l}\text { Both } \\
N=14\end{array}$ \\
\hline$\geq 5 \%$ IOP reduction from baseline to week 12 & $339(88.5)$ & $182(87.5)$ & $145(90.1)$ & $12(85.7)$ \\
\hline$\geq 15 \%$ IOP reduction from baseline to week 12 & $298(77.8)$ & $156(75.0)$ & $131(81.4)$ & $11(78.6)$ \\
\hline $\mathrm{IOP}<16 \mathrm{mmHg}$ at week 12 & $128(33.4)$ & $76(36.5)$ & $49(30.4)$ & $3(21.4)$ \\
\hline \multirow[t]{3}{*}{ IOP $<18 \mathrm{mmHg}$ at week 12} & $255(66.6)$ & $138(66.3)$ & $107(66.5)$ & $10(71.4)$ \\
\hline & \multicolumn{3}{|c|}{ Gender } & \\
\hline & $\begin{array}{c}\text { Male } \\
N=179\end{array}$ & & $\begin{array}{l}\text { Female } \\
N=204\end{array}$ & \\
\hline$\geq 5 \%$ IOP reduction from baseline to week 12 & $160(89.4)$ & & $179(87.7)$ & \\
\hline$\geq 15 \%$ IOP reduction from baseline to week 12 & $146(81.6)$ & & $152(74.5)$ & \\
\hline IOP $<16 \mathrm{mmHg}$ at week 12 & $64(35.8)$ & & $64(31.4)$ & \\
\hline IOP $<18 \mathrm{mmHg}$ at week 12 & $126(70.4)$ & & $129(63.2)$ & \\
\hline
\end{tabular}

Both = OAG and OHT; IOP = intraocular pressure; ITT = intent-to-treat population;

$\mathrm{OAG}=$ open-angle glaucoma; $\mathrm{OHT}=$ ocular hypertension.

similar designs, it is notable that the mean IOP reduction of $5.4 \mathrm{mmHg}$ over 12 weeks was greater than reductions reported previously $[32,33]$. Thus, an average IOP reduction of $3.7 \mathrm{mmHg}$ (from 21.6 to $17.9 \mathrm{mmHg}$ ) in 2 months was reported for 53 patients switched from timolol monotherapy to latanoprost/timolol FC [32]. In a study that monitored changes in IOP during the first 6 months following a switch to the FC, Dunker et al. [33] found statistically significant mean IOP reductions of $3.3 \mathrm{mmHg}$ among 902 OAG patients and $3.4 \mathrm{mmHg}$ in 42 patients with OHT.

An unknown proportion of IOP reductions reported in switch studies may have been attributable to the Hawthorne effect, the tendency for subjects to improve in response to the fact of being studied rather than in response to the experimental change [34,35]. Findings of six studies [36$41]$ in which one group or eye continued on the baseline ocular hypotensive therapy while the other group or eye switched to another agent for periods ranging from 21 days to 6 months are inconsistent with regard to the potential magnitude of such an effect. Effect sizes ranged from -0.37 $\mathrm{mmHg}$ in 115 patients continued for 6 months on dual therapy that included a beta-blocker [40] to $-3.1 \mathrm{mmHg}$ in five patients continued for 12 weeks on timolol [38]. Mean IOP reductions in the control group in each of these six studies were substantially smaller than the $-5.4 \mathrm{mmHg}$ mean change from baseline to week 12 observed herein.

No change in visual acuity was noted at the end of this relatively short-term study in these patients with good vision at baseline, and no clinically relevant changes in glaucoma symptoms based on GSS scores were found. The latter result may reflect the fact that the study population presented at baseline with GSS scores similar to those observed in the reference group (without glaucoma) of the study that assessed the validity and reliability of the GSS [18]. In addition, the GSS may not be sensitive enough to assess short-term changes in symptoms in our patient group. The authors noted that the population used to test the validity and reliability of the GSS "... may not accurately represent a community-based setting, where populations of persons with glaucoma are likely to have milder disease and/or are likely to receive treatments" [18].

As has been reported previously [12-17], the FC was well tolerated. The most common adverse events were related to the eye and were consistent with known adverse events associated with latanoprost or timolol. The six serious adverse events were not considered to be related to study treatment. 


\begin{tabular}{|c|c|c|c|c|}
\hline & \multirow[b]{2}{*}{$\begin{array}{c}\text { All } \\
\mathbf{N}=\mathbf{3 8 3}\end{array}$} & \multicolumn{3}{|c|}{ Diagnosis } \\
\hline & & $\begin{array}{c}\text { OAG } \\
N=208\end{array}$ & $\begin{array}{c}\text { OHT } \\
N=161\end{array}$ & $\begin{array}{l}\text { Both } \\
N=14\end{array}$ \\
\hline \multicolumn{5}{|c|}{ Global GSS score } \\
\hline Baseline & $86.15 \pm 15.73$ & $84.99 \pm 15.89$ & $87.29 \pm 15.54$ & $89.41 \pm 15.67$ \\
\hline Week 12 & $88.49 \pm 14.32$ & $86.81 \pm 15.91$ & $90.19 \pm 12.50$ & $91.59 \pm 8.50$ \\
\hline \multicolumn{5}{|c|}{ Non-visual GSS score } \\
\hline Baseline & $84.60 \pm 17.09$ & $84.70 \pm 16.14$ & $84.34 \pm 18.04$ & $86.11 \pm 20.52$ \\
\hline Week 12 & $86.78 \pm 15.40$ & $84.74 \pm 17.05$ & $89.08 \pm 12.95$ & $88.10 \pm 14.88$ \\
\hline \multicolumn{5}{|c|}{ Visual GSS score } \\
\hline Baseline & $87.76 \pm 18.46$ & $85.97 \pm 19.95$ & $89.54 \pm 16.81$ & $92.79 \pm 11.08$ \\
\hline \multirow[t]{3}{*}{ Week 12} & $89.76 \pm 17.26$ & $88.33 \pm 19.18$ & $91.06 \pm 15.19$ & $94.64 \pm 7.70$ \\
\hline & \multicolumn{3}{|c|}{ Gender } & \\
\hline & $\begin{array}{c}\text { Male } \\
N=179\end{array}$ & & $\begin{array}{l}\text { Female } \\
N=204\end{array}$ & \\
\hline \multicolumn{5}{|c|}{ Global GSS score } \\
\hline Baseline & $87.28 \pm 15.24$ & & $85.19 \pm 16.13$ & \\
\hline Week 12 & $90.05 \pm 13.96$ & & $87.08 \pm 14.55$ & \\
\hline \multicolumn{5}{|c|}{ Non-visual GSS score } \\
\hline Baseline & $86.52 \pm 15.77$ & & $82.95 \pm 18.02$ & \\
\hline Week 12 & $88.81 \pm 14.17$ & & $84.90 \pm 16.27$ & \\
\hline \multicolumn{5}{|c|}{ Visual GSS score } \\
\hline Baseline & $88.15 \pm 18.29$ & & $87.43 \pm 18.64$ & \\
\hline Week 12 & $90.81 \pm 16.40$ & & $88.83 \pm 17.98$ & \\
\hline
\end{tabular}

Both = OAG and OHT; ITT = intent-to-treat population; $\mathrm{OAG}=$ open-angle glaucoma;

$\mathrm{OHT}=$ ocular hypertension; $\mathrm{SD}=$ standard deviation.

While this study's open-label observational design may better reflect actual clinical practice than controlled clinical trials, the study had several limitations. In particular, not all of the investigators used applanation tonometry to measure IOP levels, and because the method of IOP measurement was not always documented, we could not analyze IOP changes stratified by tonometry type. Although every effort was made to ensure consistency of procedures and data recording across centers, the extent of variation among practices is unknown. The 12-week follow-up period was not sufficient to detect long-term changes in visual acuity or GSS scores. Finally, we considered a favorable response to the $\mathrm{FC}$ to be an additional $10 \%$ IOP reduction, an arbitrary cutoff point. Regression to the mean [26] may have accounted for reductions in some of the $84.9 \%$ of subjects counted as responders, but it is notable that $77.8 \%$ of subjects recorded IOP reductions of at least $15 \%$ from baseline to week 12.

\section{Conclusions}

Reducing IOP levels slows down disease progression in glaucoma patients [1-4] and delays progression to glaucoma in OHT patients [5]. Our findings support the use of latanoprost/timolol FC in routine clinical practice in 
Table 6: Adverse events by body system, n (\%)

\begin{tabular}{|c|c|c|}
\hline & $\begin{array}{l}\text { All causality adverse events } \\
\qquad \mathrm{N}=391\end{array}$ & $\begin{array}{c}\text { Treatment-related adverse } \\
\text { events } \\
\mathrm{N}=391\end{array}$ \\
\hline Any adverse event & $89(22.8)$ & $60(15.3)$ \\
\hline Discontinued due to adverse event & $22(5.6)$ & $20(5.1)$ \\
\hline \multicolumn{3}{|l|}{ System Organ Class } \\
\hline Cardiac disorders & $3(0.8)$ & $2(0.5)$ \\
\hline Ear and labyrinth disorders & $4(1.0)$ & $3(0.8)$ \\
\hline Eye disorders & $40(10.2)$ & $34(8.7)$ \\
\hline Gastrointestinal disorders & $6(1.5)$ & $3(0.8)$ \\
\hline General disorders and administration site conditions & $11(2.8)$ & $8(2.0)$ \\
\hline Immune system disorders & $2(0.5)$ & $2(0.5)$ \\
\hline Infections and infestations & $8(2.0)$ & $1(0.3)$ \\
\hline Injury, poisoning, and procedural complications & $2(0.5)$ & $1(0.3)$ \\
\hline Investigations & $2(0.5)$ & $2(0.5)$ \\
\hline Metabolism and nutrition disorders & $1(0.3)$ & $1(0.3)$ \\
\hline Musculoskeletal and connective tissue disorders & $2(0.5)$ & - \\
\hline Nervous system disorders & $12(3.1)$ & $8(2.0)$ \\
\hline Psychiatric disorders & $8(2.0)$ & $6(1.5)$ \\
\hline Reproductive system and breast disorders & $1(0.3)$ & $1(0.3)$ \\
\hline Respiratory, thoracic, and mediastinal disorders & $4(1.0)$ & $3(0.8)$ \\
\hline Skin and subcutaneous tissue disorders & $10(2.6)$ & $9(2.3)$ \\
\hline Surgical and medical procedures & $2(0.5)$ & - \\
\hline Vascular disorders & $6(1.5)$ & $2(0.5)$ \\
\hline
\end{tabular}

patients whose IOP is insufficiently controlled on betablocker monotherapy. Patients with higher baseline IOP levels and who do not experience adverse events are most likely to achieve a positive response to the FC.

\section{Competing interests}

The authors have no proprietary interests. The study was supported by Pfizer France.

\section{Authors' contributions}

ES participated in the study design, acquisition of data, analysis and interpretation of data, drafting of the manuscript, critical revision of the manuscript for important intellectual content, and study supervision. JFR participated in the study design, acquisition of data, and critical revision of the manuscript. CB and J-PN participated in the study design and critical revision of the manuscript. PD participated in the study design, analysis and interpretation of data, drafting of the manuscript, and revision of the manuscript. $A B$ participated in the acquisition of data and critical revision of the manuscript. JPR participated in the study design, critical revision of the manuscript, and study supervision. All authors read and approved the final manuscript.

\section{Acknowledgements}

The results of this study were presented in part at the $17^{\text {th }}$ Congress of the European Society of Ophthalmology (SOE); June 13-16, 2009; Amsterdam, the Netherlands.

Editorial support, including contributing to the first draft of the paper, revising based on author comments, and styling the paper for journal submission, was provided by Jane G. Murphy, PhD, of Zola Associates and was funded by Pfizer France.

\section{Author Details}

${ }^{1}$ Centre Ophtalmologique Kléber, 50, Cours Franklin Roosevelt, 69006 Lyon, France, ${ }^{2}$ Ophthalmology Department, Hôpital Huriez, 1, Place de Verdun, 59037 Lille, France, ${ }^{3}$ Ophthalmology Department 3, Centre Hospitalier National des Quinze-Vingts, 28, Rue de Charenton, Paris Cedex 12, France,

${ }^{4}$ Ophthalmology Department, Hôpital Général, 3, Rue du Faubourg Raines, 21033 Dijon, France, 5 Ophthalmology Department, Hôpital Edouard Herriot, 5, Place d'Arsonval, 690437 Lyon Cedex 03, France, 6 Ophthalmology Department 2, Centre Hospitalier National des Quinze-Vingts, 28, Rue de Charenton, Paris Cedex 12, France and 7 Ophthalmology Department, Hôpital d'Instruction des Armées du Val de Grâce, 74, Boulevard du Port Royal, Paris Cedex 05, France

Received: 24 November 2009 Accepted: 26 March 2010

Published: 26 March 2010 


\section{References}

1. AGIS Investigators: The Advanced Glaucoma Intervention Study (AGIS): 7: The relationship between control of intraocular pressure and visual field deterioration. Am J Ophthalmol 2000, 130:429-440.

2. Collaborative Normal-Tension Glaucoma Study Group: The effectiveness of intraocular pressure reduction in the treatment of normal-tension glaucoma. Am J Ophthalmol 1998, 126:498-505.

3. Heijl A, Leske MC, Bengtsson B, Hyman L, Bengtsson B, Hussein M, Early Manifest Glaucoma Trial Group: Reduction of intraocular pressure and glaucoma progression: results from the Early Manifest Glaucoma Trial. Arch Ophthalmol 2002, 120:1268-1279.

4. Leske MC, Heijl A, Hussein M, Bengtsson B, Hyman L, Komaroff E, Early Manifest Glaucoma Trial Group: Factors for glaucoma progression and the effect of treatment: the Early Manifest Glaucoma Trial. Arch Ophthalmol 2003, 121:48-56.

5. Kass MA, Heuer DK, Higginbotham EJ, Johnson CA, Keltner JL, Miller JP, Parrish RK, Wilson MR, Gordon MO: The Ocular Hypertension Treatment Study: a randomized trial determines that topical ocular hypotensive medication delays or prevents the onset of primary open-angle glaucoma. Arch Ophthalmol 2002, 120:701-713.

6. European Glaucoma Society Terminology and Guidelines for Glaucoma, IInd ed. Savona, Italy: DOGMA; 2008.

7. Patel SC, Spaeth GL: Compliance in patients prescribed eyedrops for glaucoma. Ophthalmic Surg 1995, 26:233-236.

8. Haynes RB, McDonald HP, Garg AX: Helping patients follow prescribed treatment: clinical applications. JAMA 2002, 288:2880-2883.

9. Roter DL, Hall JA, Merisca R, Nordstrom B, Cretin D, Svarstad B: Effectiveness of interventions to improve patient compliance: a metaanalysis. Med Care 1998, 36:1138-1161.

10. Sleath B, Robin AL, Covert D, Byrd JE, Tudor G, Svarstad B: Patientreported behavior and problems in using glaucoma medications. Ophthalmology 2006, 113:431-436.

11. Xalacom '. Summary of Product Characteristics. November 2007. Electronic Medicines Compendium [http://emc.medicines.org.uk/ medicine/7735/SPC/Xalacom+eye+drops\%2c+solution/]. Accessed: November 16, 2009

12. Diestelhorst M, Larsson LI, European Latanoprost Fixed Combination Study Group: A 12 week study comparing the fixed combination of latanoprost and timolol with the concomitant use of the individual components in patients with open angle glaucoma and ocular hypertension. Br J Ophthalmol 2004, 88:199-203.

13. Diestelhorst M, Larsson LI, European-Canadian Latanoprost Fixed Combination Study Group: A 12-week, randomized, double-masked, multicenter study of the fixed combination of latanoprost and timolol in the evening versus the individual components. Ophthalmology 2006, 113:70-76

14. Higginbotham EJ, Diestelhorst M, Pfeiffer N, Rouland JF, Alm A: The efficacy and safety of unfixed and fixed combinations of latanoprost and other antiglaucoma medications. Surv Ophthalmol 2002,47(Suppl 1):S133-S140.

15. Higginbotham EJ, Feldman $R$, Stiles $M$, Dubiner $H$, Fixed Combination Investigative Group: Latanoprost and timolol combination therapy vs monotherapy: one-year randomized trial. Arch Ophthalmol 2002, 120:915-922.

16. Pfeiffer N, European Latanoprost Fixed Combination Study Group: A comparison of the fixed combination of latanoprost and timolol with its individual components. Graefes Arch Clin Exp Ophthalmol 2002, 240:893-899.

17. Shin DH, Feldman RM, Sheu WP, Fixed Combination Latanoprost/Timolol Study Group: Efficacy and safety of the fixed combinations latanoprost/ timolol versus dorzolamide/timolol in patients with elevated intraocular pressure. Ophthalmology 2004, 111:276-282

18. Lee BL, Gutierrez P, Gordon M, Wilson MR, Cioffi GA, Ritch R, Sherwood M, Mangione CM: The Glaucoma Symptom Scale. A brief index of glaucoma-specific symptoms. Arch Ophthalmol 1998, 116:861-866.

19. Baudouin C, Rouland JF, Nordmann JP, Bron A, Pelen F: [Efficacy of firstor second-line latanoprost on intraocular pressure and ocular symptoms in patients with open-angle glaucoma or ocular hypertension]. J FrOphtalmol 2006, 29:615-624.

20. Ringsdorf L, McGwin G Jr, Owsley C: Visual field defects and visionspecific health-related quality of life in African Americans and whites with glaucoma. J Glaucoma 2006, 15:414-418.
21. Rossi GC, Tinelli C, Pasinetti GM, Milano G, Bianchi PE: Dry eye syndromerelated quality of life in glaucoma patients. Eur J Ophthalmo/ 2009, 19:572-579.

22. Rulo AH, Greve EL, Geijssen HC, Hoyng PF: Reduction of intraocular pressure with treatment of latanoprost once daily in patients with normal-pressure glaucoma. Ophthalmology 1996, 103:1276-1282.

23. Hedman K, Alm A: A pooled-data analysis of three randomized, doublemasked, six-month clinical studies comparing the intraocular pressure reducing effect of latanoprost and timolol. Eur J Ophthalmol 2000 10:95-104.

24. Hedman K, Larsson LI: The effect of latanoprost compared with timolol in African-American, Asian, Caucasian, and Mexican open-angle glaucoma or ocular hypertensive patients. Surv Ophthalmol 2002, 47(Suppl 1):S77-S89.

25. Ang A, Reddy MA, Shepstone L, Broadway DC: Long term effect of latanoprost on intraocular pressure in normal tension glaucoma. $\mathrm{Br} J$ Ophthalmol 2004, 88:630-634.

26. Dawson-Saunders B, Trapp RB: Basic and Clinical Biostatistics. Norwalk, CT: Appleton \& Lange; 1990

27. Tsai JC, McClure CA, Ramos SE, Schlundt DG, Pichert JW: Compliance barriers in glaucoma: a systematic classification. J Glaucoma 2003, 12:393-398.

28. Zimmerman TJ, Hahn SR, Gelb L, Tan H, Kim EE: The impact of ocular adverse effects in patients treated with topical prostaglandin analogs: changes in prescription patterns and patient persistence. J Ocul Pharmacol Ther 2009, 25:145-152.

29. AGIS Investigators: The Advanced Glaucoma Intervention Study (AGIS): 12: Baseline risk factors for sustained loss of visual field and visual acuity in patients with advanced glaucoma. Am J Ophthalmol 2002, 134:499-512.

30. Lichter PR, Musch DC, Gillespie BW, Guire KE, Janz NK, Wren PA, Mills RP, CIGTS Study Group: Interim clinical outcomes in the Collaborative Initial Glaucoma Treatment Study comparing initial treatment randomized to medications or surgery. Ophthalmology 2001, 108:1943-1953.

31. Friedman DS, Wilson MR, Liebmann JM, Fechtner RD, Weinreb RN: An evidence-based assessment of risk factors for the progression of ocular hypertension and glaucoma. Am J Ophthalmol 2004, 138(3 Suppl):S19-S31.

32. Hamacher T, Schinzel M, Schölzel-Klatt A, Neff HM, Maier H, Schlaffer G, Beausencourt E, Jütte M, Scholz R, Lorger C, Stewart WC: Short term efficacy and safety in glaucoma patients changed to the latanoprost $0.005 \% /$ timolol maleate $0.5 \%$ fixed combination from monotherapies and adjunctive therapies. Br J Ophthalmol 2004, 88:1295-1298.

33. Dunker S, Schmucker A, Maier H, Latanoprost/Timolol Fixed Combination Study Group: Tolerability, quality of life, and persistency of use in patients with glaucoma who are switched to the fixed combination of latanoprost and timolol. Adv Ther 2007, 24:376-386.

34. McCarney R, Warner J, Iliffe S, van Haselen R, Griffin M, Fisher P: The Hawthorne Effect: a randomized, controlled trial. BMCMed Res Methodol 2007, 7:30

35. Franke RH, Kaul JD: The Hawthorne experiments: First statistical interpretation. Am Sociol Rev 1978, 43:623-643.

36. Casson RJ, Liu L, Graham SL, Morgan WH, Grigg JR, Galanopoulos A Crawford A, House PH: Efficacy and safety of bimatoprost as replacement for latanoprost in patients with glaucoma or ocular hypertension: a uniocular switch study. J Glaucoma 2009, 18:582-588.

37. Hatanaka M, Reis A, Sano ME, Susanna R Jr: Additive intraocular pressure reduction effect of fixed combination of maleate timolol $0.5 \%$ / dorzolamide $2 \%$ (Cosopt) on monotherapy with latanoprost (Xalatan) in patients with elevated intraocular pressure: a prospective, 4-week open-label, randomized, controlled clinical trial. J Glaucoma 2009 in press.

38. Novack GD, David R, Lee PF, Freeman MI, Duzman E, Batoosingh AL: Effect of changing medication regimens in glaucoma patients. Ophthalmologica 1988, 196:23-28.

39. Olander K, Zimmerman TJ, Downes N, Schoenfelder J, Xalacom/ Latanoprost Study Group: Switching from latanoprost to fixed combination latanoprost-timolol: a 21-day, randomized, doublemasked, active-control study in patients with glaucoma and ocular hypertension. Clin Ther 2004, 26:1619-1629.

40. Pillunat LE, Larsson LI, European and Canadian Latanoprost Study Group: Intraocular pressure after replacement of current dual therapy with 
latanoprost monotherapy in patients with open angle glaucoma. Br J Ophthalmol 2003, 87:1492-1496.

41. Rhee DJ, Peace JH, Mallick S, Landry TA, Bergamini MV, the Study Group: A study of the safety and efficacy of travoprost $0.004 \% /$ timolol $0.5 \%$ ophthalmic solution compared to latanoprost $0.005 \%$ and timolol $0.5 \%$ dosed concomitantly in patients with open-angle glaucoma or ocular hypertension. Clin Ophthalmol 2008, 2:313-319.

Pre-publication history

The pre-publication history for this paper can be accessed here: http://www.biomedcentral.com/1471-2415/10/10/prepub

doi: $10.1186 / 1471-2415-10-10$

Cite this article as: Sellem et al., Predictors of additional intraocular pressure reduction in patients changed to latanoprost/timolol fixed combination BMC Ophthalmology 2010, 10:10

Submit your next manuscript to BioMed Central and take full advantage of:

- Convenient online submission

- Thorough peer review

- No space constraints or color figure charges

- Immediate publication on acceptance

- Inclusion in PubMed, CAS, Scopus and Google Scholar

- Research which is freely available for redistribution

Submit your manuscript at www.biomedcentral.com/submit
C Biomed Central 